\title{
Universitarias en el antifranquismo. Mujeres, movilización estudiantil y feminismo, 1960-1975
}

\author{
Female University Students in Antifrancoism. \\ Women, Student Movement and Feminism, 1960-1975
}

\author{
Mónica Moreno Seco* \\ Universidad de Alicante \\ ORCID ID: 0000-0002-3219-8790
}

$\begin{array}{ll}\text { Recibido: } & 18 / 02 / 2020 \\ \text { Aceptado: } & 27 / 03 / 2020\end{array}$

DOI: https://doi.org/10.20318/cian.2020.5428

Resumen: La experiencia colectiva de las estudiantes universitarias españolas que se movilizaron contra la dictadura franquista no es muy conocida, a pesar de que en los años sesenta y setenta tuvo lugar el ingreso masivo de mujeres a las aulas universitarias y de que un número destacado de ellas participaron en las protestas, alcanzando en algunos casos puestos de liderazgo. Por otro lado, en el movimiento estudiantil adquirieron una especial relevancia nuevas costumbres y relaciones personales. Por todo ello, nos preguntamos si esta composición más equilibrada y estos nue-
Abstract: The collective experience of the female Spanish university students who protested against the francoist dictatorship is not well known, unlike in the sixties and the seventies there was a mass intake of women into the Spanish university and a significant number of them became involved in the protests there, a few of whom reached positions of leadership within the university organizations. In addition, in the student movement new habits and personal relationships took on importance. In this paper, we raise the question of whether this more balanced com-

"monica.moreno@ua.es. Este trabajo se ha realizado en el marco del proyecto "Género, compromiso y transgresión en España, 1890-2016" (FEM2016-76675-P), financiado por el Ministerio de Economía y Competitividad. Agradezco la información facilitada por Alberto Carrillo-Linares sobre estudiantes de la Universidad de Sevilla. 
vos intereses introdujeron cambios o si por el contrario pasaron inadvertidos. Por último, se reflexiona sobre la tensión entre la fantasía de la igualdad y los frecuentes casos de discriminación en el mundo universitario, y sobre cómo influyó la experiencia de la militancia estudiantil en las jóvenes que comenzaron a interesarse por el feminismo y pronto formaron parte de grupos de mujeres. Este texto aborda estas cuestiones desde una perspectiva metodológica que incorpora la intersección entre las categorías de género, edad y clase.

Palabras clave: mujeres, universidad, antifranquismo, juventud, transgresión. position and these new interests really led to significant changes. Finally, we reflect upon the tension between the fantasy of equality and the frequent cases of discrimination in the universities. We also consider how the experience of militancy in the student movement influenced the young women who began to take an interest in feminism and soon joined women's groups. This text approaches these themes from a methodological perspective which incorporates the intersection between the categories of gender, age and class.

Keywords: women, university, antifrancoism, youth, transgression.

\section{Introducción}

El movimiento estudiantil contribuyó de manera decisiva a la erosión de la dictadura franquista, por lo que ha sido objeto de numerosos y sólidos estu$\operatorname{dios}^{1}$. No obstante, a diferencia de lo que ha sucedido con otros focos del antifranquismo, la experiencia de las mujeres universitarias no ha despertado un gran interés. En 2004, Rodríguez Tejada publicó un interesante artículo centrado en la Universidad de Valencia, en el que insistió en revalorizar la militancia de las mujeres, con frecuencia considerada secundaria, pero también subrayó que el movimiento estudiantil les abrió amplios cauces personales y públicos ${ }^{2}$. A pesar de ello, desde entonces solo contamos con referencias puntuales a líderes estudiantiles y, eso sí, un destacado volumen de biografías, memorias y testimonios. Por el contrario, los estudios sobre los "años 1968" en Europa incorporan de manera mayoritaria una perspectiva de género, al resaltar las contradicciones en los discursos y prácticas de la cultura juvenil contestataria de la época, uno de cuyos espacios privilegiados de debate y actuación fueron las universidades ${ }^{3}$. En este texto se propone

${ }^{1}$ Un balance reciente en Alberto Carrillo-Linares y Sergio Rodríguez Tejada, "1968 y los estudiantes españoles: del antifranquismo a la revolución”, en Las convulsiones del 68. España y el sur de Europa, coord. Abdón Mateos López y Emanuele Treglia (Madrid: UNED, 2019), 29-63.

${ }^{2}$ Sergio Rodríguez Tejada, "Compañeras: la militancia de las mujeres en el movimiento estudiantil antifranquista en Valencia”, Historia del Presente 4 (2004): 123-146.

${ }^{3}$ Lessie Jo Frazier y Deborah Cohen, eds., Gender and Sexuality in 1968. Transformative Politics in the Cultural Imagination (Nueva York : Palgrave MacMillan, 2009). Michelle Zancarini-Fournel, “Genre et politique: Les années 68”, Vingtième Siècle. Revue d'histoire 75 (2002): 133-143. 
reflexionar sobre la experiencia colectiva de las estudiantes universitarias españolas recogiendo este bagaje y desde una perspectiva metodológica que incorpore la intersección entre las categorías de género, edad y clase.

La pertinencia de estudiar la experiencia de las mujeres en las movilizaciones universitarias del segundo franquismo se sustenta en varios elementos. El primero de ellos reside en que fue el momento de arranque del ingreso masivo de mujeres a las aulas universitarias: en el curso 1966-67 representaban un 30\% del alumnado (aunque en Filosofía y Letras alcanzaban un 60\%), mientras en el curso 1977-78 ya eran el 40\%, de nuevo con predominio de Filosofía y Letras ${ }^{4}$. Aunque la gran mayoría provenía de las clases medias, la decisión de cursar estudios universitarios en los años sesenta suponía una transgresión de las normas que regían la vida de las jóvenes de la época, que se reflejaban en la pervivencia de prejuicios sobre su capacidad intelectual o su aspecto físico. Unos estereotipos que fueron cambiando lentamente en la década siguiente.

En segundo término, había muchas mujeres en la movilización universitaria, al igual que en otros ámbitos como el obrero y vecinal, por mencionar algunos, aunque no fuera en condiciones de igualdad con los hombres. Por ello, tiene sentido preguntarse si esta presencia destacada introdujo especificidades o si por el contrario pasó inadvertida, teniendo en cuenta por ejemplo que las facultades de Filosofía y Letras fueron las más movilizadas. Carrillo-Linares ha señalado que el movimiento estudiantil ofreció un marco de aprendizaje político para parte de la juventud española, e insiste en que fue una experiencia determinante para la incorporación de muchas mujeres a la política. ${ }^{5}$ Hubo otros medios, pero desde luego el universitario fue uno destacado. Los partidos de la nueva izquierda, que tenían una matriz universitaria y un importante porcentaje de estudiantes entre sus filas, se caracterizaron por una numerosa militancia de mujeres, y en ocasiones fueron asumiendo las demandas del feminismo a sus agendas ${ }^{6}$. En los años setenta, se convirtieron en el eje de las movilizaciones en las universidades, cuestionando la hegemonía que el PCE había detentado en la década anterior.

${ }^{4}$ Judith Carbajo Vázquez, "Mujeres y educación (1965-1975)", en Historia de las mujeres en España. Siglo XX, dir. Josefina Cuesta Bustillo, vol. II (Madrid: Instituto de la Mujer, 2003), 223-253.

${ }^{5}$ Alberto Carrillo-Linares, "Movimiento estudiantil antifranquista, cultura política y transición a la democracia", Pasado y Memoria. Revista de Historia Contemporánea 5, (2006): 167.

${ }^{6}$ Mónica Moreno Seco, "Sexo, Marx y nova cançó. Género, política y vida privada en la juventud comunista de los años setenta", Historia Contemporánea 54 (2017): 47-84. 
Por último, también resulta necesario analizar las vivencias de las mujeres en las universidades por la trascendencia que en el movimiento estudiantil y en general en la contracultura juvenil del momento se concedió a las relaciones personales y la sexualidad. Como indicaba Colomer ya en 1978, "lo personal y lo político formaban parte de una misma concepción y de un mismo activismo renovador"7. El carácter antiautoritario de los grupos universitarios más politizados les hizo cuestionar las jerarquías familiares, académicas, políticas y también entre hombres y mujeres ${ }^{8}$. En suma, en estos años fue creciente la convivencia de los y las jóvenes en el movimiento estudiantil "con un componente de camaradería igualitaria -pero no menos de atracción afectiva, intelectual y sexual mutua-" ${ }^{\text {" }}$.

En este texto la intersección entre género, clase y edad se erige en una herramienta metodológica de primer orden. Las activistas universitarias articularon una identidad compleja y conflictiva como mujeres jóvenes de clase media, pues no siempre se reconocieron como tales. Por otro lado, proyectaron imágenes contrapuestas, que basculaban entre la subordinación y la rebeldía, que desde una mirada masculina provocaban tanto rechazo por ocupar un espacio que pretendidamente no les correspondía, como atracción física, reduciéndolas a cuerpos sexuados.

En primer lugar, la contestación juvenil se suele identificar con varones de clase media, que dejan fuera del foco otras realidades ${ }^{10}$. En consecuencia, introducir la categoría de género en el estudio de la movilización estudiantil y antifranquista permite detectar las contradicciones y paradojas entre los proyectos políticos y las prácticas militantes, y reflexionar sobre las diversas estrategias desplegadas por las mujeres en contextos masculinizados. Pero también contribuye a ampliar los límites de la contestación política en el desgaste de la dictadura, incluyendo lo público y lo privado, y concediendo mayor espacio a la creación de subjetividades transgresoras o en proceso de cambio ${ }^{11}$. En segundo lugar, la gran mayoría de las estudian-

\footnotetext{
${ }^{7}$ Josep María Colomer, “¿Dónde están los estudiantes radicales del 68?”, Triunfo, 17 de junio de 1978.

${ }^{8}$ José Álvarez Cobelas, Envenenados de cuerpo y alma. La oposición universitaria al franquismo en Madrid (1939-1970) (Madrid: Siglo XXI, 2004), 193.

${ }^{9}$ Elena Hernández Sandoica, Miguel Ángel Ruiz Carnicer y Marc Balcó Lacomba, Estudiantes contra Franco (1939-1975). Oposición política y movilización juvenil (Madrid: La Esfera de los Libros, 2007), 225.

${ }^{10}$ Germán Labrador Méndez, Culpables por la literatura. Imaginación política y contracultura en la transición española (1968-1986) (Madrid: Akal, 2017), 72.

${ }^{11}$ Sobre las relaciones entre género y compromiso, Karine Bergès y Mercedes Yusta Rodrigo. "Introduction. Femmes et politique, le genre et l'engagement", en Résistantes, militantes,
} 
tes universitarias procedían de familias de clase media o incluso de estratos privilegiados. Esta circunstancia facilitó su ingreso en la universidad y les proporcionó una cierta protección ante la represión, pero a la vez, en unas culturas políticas que mitificaban el mundo obrero, eran minusvaloradas como sujetos políticos ${ }^{12}$.

En tercer y último lugar, cabe recordar que en los años sesenta y setenta se conformó una cultura juvenil rebelde en el mundo occidental, de la que participó la juventud española, en especial la universitaria. Sin embargo, el análisis de la juventud, consustancial a la investigación sobre estudiantes, implica algunas dificultades. Entre ellas, la temporalidad del paso por las aulas, que se traduce en una renovación constante de los y las integrantes del movimiento estudiantil ${ }^{13}$. De hecho, el periodo estudiado se podría dividir en dos etapas y quizá dos generaciones juveniles. En los sesenta, primaba la preocupación por las cuestiones académicas (deseo de democratizar la universidad y por extensión el país), se impulsaron sindicatos de estudiantes, auspiciados sobre todo por el PCE, aunque no solo, y se recurría todavía a una estética convencional. A partir de 1965-1968, se politizaron las demandas (proyectos revolucionarios, rechazo de la universidad como institución burguesa), irrumpió la nueva izquierda y se extendieron nuevas apariencias y costumbres. Estas transformaciones impactaron de manera especial entre las mujeres, quienes se enfrentaron no solo a las autoridades académicas y políticas, sino también al control familiar y social. Otra dificultad que surge al analizar la juventud reside en la diversidad de discursos e imágenes que existen sobre ella en cada contexto histórico, desde la mitificación a la demonización ${ }^{14}$. En ese sentido, la intersección entre edad y género suele reforzar la pretendida subordinación de las jóvenes, de manera que son percibidas como seres dependientes a quienes se niega una agencia, pero cabe preguntarse cómo actuaron y cómo fueron descritas en momentos de contestación juvenil y política ${ }^{15}$.

citoyennes. L'engagement politique des femmes aux xxe et xxie siècles, dir. Karine Bergès y otras (Rennes: PUR, 2015), 7-15.

${ }^{12}$ Sobre la cultura obrera, Giaime Pala, "Entre paternalismo e igualitarismo. El PSUC y la cuestión de la mujer en los años del tardofranquismo", Mientras Tanto 97 (2005): 133-148.

${ }^{13}$ Eduardo González Calleja, "Rebelión en las aulas: un siglo de movilizaciones estudiantiles en España (1865-1968)", Ayer 59 (2005): 21-49.

${ }^{14}$ Incluso en el ámbito académico, según Juan Carlos Revilla Castro, "La construcción discursiva de la juventud: lo general y lo particular", Papers, 63/64 (2001): 103-122.

${ }^{15}$ Como se plantea en Mónica Moreno Seco y Bárbara Ortuño Martínez, "Presentación" al dosier "Género, juventud y compromiso", Ayer 100 (2015): 13-20. 
Por otro lado, existió una cierta fantasía de igualdad, una percepción que arrojaba una imagen de equidad en el trato y en los intereses en el mundo universitario, que no siempre se correspondió con la experiencia cotidiana de unas relaciones de género desiguales dentro del movimiento ${ }^{16}$. En este texto nos preguntaremos por el alcance y las consecuencias de estas tensiones, que orientaron a numerosas universitarias antifranquistas a militar en el movimiento feminista.

\section{La universidad como espacio de transgresión}

Para la gran mayoría de jóvenes que ingresaron en la universidad en los años sesenta, la universidad se convirtió en un ámbito de descubrimiento, de apertura de horizontes culturales, políticos y personales, que en el caso de las mujeres tuvo un gran impacto, pues implicó toda una "revolución interior"17. Algunos testimonios califican esta experiencia en términos de "ruptura" o "hito" en sus trayectorias vitales ${ }^{18}$.

La propia decisión de cursar estudios universitarios supuso para muchas una transgresión de los proyectos de vida a los que estaban destinadas. Asunción Ventura fue una de las pocas mujeres de su pueblo, en Castellón, que acudió a Valencia a estudiar, opción que provocó tensiones familiares y que le permitió empezar a cuestionarse muchos de los presupuestos en los que se había educado ${ }^{19}$. En general, la valoración que solían hacer sobre el nivel intelectual del profesorado era bastante negativa, con algunas excepciones. Sin embargo, la universidad significó abandonar el hogar familiar para trasladarse a ciudades grandes, asistir a actos culturales alternativos, acceder a lecturas deslumbrantes, fumar y frecuentar bares, participar en movilizaciones y protestas, adoptar nuevos hábitos. Como recuerda $\mathrm{M}^{\mathrm{a}} \mathrm{An}-$ tonia García de León:

${ }^{16} \mathrm{Al}$ igual que sucedió en otros países europeos, como recogen Rebecca Clifford, Robert Gildea y Anette Warring, "Gender and sexuality”, en Europe's 1968. Voices of Revolt, eds. Robert Gildea, James Mark y Anette Warring (Oxford: Oxford University Press, 2013), 239-257.

${ }^{17}$ Rodríguez Tejada, “Compañeras”, 139.

${ }^{18}$ Entrevista a Isabel Morant (en María Antonia García de León, Rebeldes ilustradas (la otra Transición) (Barcelona: Anthropos, 2008), 106) y entrevista a Elena Simón [citada el 16 de diciembre de 2019]: disponible en https://feministasvalencianas.wordpress.com/nievessimon-elena-simon/ respectivamente.

${ }^{19}$ Entrevista a Asunción Ventura [citada el 17 de diciembre de 2019]: disponible en https://feministasvalencianas.wordpress.com/asuncion-ventura/ 
si eras universitaria, a la fuerza tenías que estar en la movida de entonces. ¡Había tal clima de agitación en la Universidad!" "Nosotros, los que tuvimos el privilegio de ser universitarios (iy era muchísimo privilegio, máxime siendo chicas!) nos hicimos modernos, los más modernos de los modernos, en tres días ${ }^{20}$.

En el mismo sentido, Maite Larrauri define su llegada a la universidad como una "catarsis absoluta", pues en ese curso lo hizo todo por primera vez: el primer porro, la primera manifestación multitudinaria, el primer contacto con grupos feministas, la primera pastilla anticonceptiva y muchas lecturas ${ }^{21}$. Una experiencia similar vivió Angustias Bertomeu, que provenía de Alicante: "yo llegué con 18 años a Valencia y bueno, pues en los tres primeros meses me caí del caballo: perdí la virginidad, tuve mi primer novio, corrí por primera vez en mi vida delante de la policía"22.

De una manera primero intuitiva y después más decidida, fue conformándose una cultura política juvenil y estudiantil, según Carrillo-Linares, que se definió en términos ideológicos y también emocionales, por confrontación a la dictadura, la autoridad familiar y académica o la moral nacional-católica, y que construyó una identidad propia a través de un lenguaje específico, redes informales de relación y la participación en actos colectivos ${ }^{23}$. Álvarez Cobelas y Rodríguez Tejada destacan, en el mismo sentido, la relevancia de las actividades culturales (seminarios, teatro universitario, cine-clubs) o de los espacios de sociabilidad juvenil como bares y pisos compartidos ${ }^{24}$. Otro foco de descubrimiento y de politización fueron las lecturas. Las referencias a Marx, Engels y Lenin o también a Simone de Beauvoir y Wilhelm Reich son muy frecuentes en los testimonios, aunque se reconoce que no siempre se entendían ${ }^{25}$.

El descontento difuso, por la pobreza cultural y el control moral franquistas, condujo a una progresiva inquietud política, que en los primeros momentos no obedecía a opciones demasiado marcadas, pero que estaban

${ }^{20}$ García de León, Rebeldes, 59 y 70.

${ }^{21}$ Entrevista a Maite Larrauri [citada el 17 de diciembre de 2019]: disponible en https:// feministasvalencianas.wordpress.com/maite-larrauri/

${ }^{22}$ Entrevista a Angustias Bertomeu [citada el 16 de diciembre de 2019]: disponible en https://feministasvalencianas.wordpress.com/angustias-bertomeu/

${ }^{23}$ Carrillo-Linares, "Movimiento estudiantil". La define como una "subcultura estudiantil" José María Maravall, Dictadura y disentimiento político. Obreros y estudiantes bajo el franquismo (Madrid: Alfaguara, 1978).

${ }^{24}$ Álvarez Cobelas, Envenenados, 351-353. Sergio Rodríguez Tejada, Zonas de libertad. IIDictadura franquista y movimiento estudiantil en la Universidad de Valencia (1965-1975) (Valencia: PUV, 2009), 227-243.

${ }^{25}$ García de León, Rebeldes, 71. 
revestidas de entusiasmo y de compañerismo. En palabras de María Gascón, estudiante en Bilbao:

Empezamos a frecuentar [reuniones]... Porque nos reuníamos y porque había mucha emoción. [...] eran mis amigos, o sea, era la gente con la que me lo pasaba bien, con la que se hablaba de cosas que no sabías muy bien, pero que parecían muy interesantes ${ }^{26}$.

Otros dos elementos esenciales que definieron la juventud universitaria progresista del momento fueron una nueva forma de experimentar la sexualidad, con sus contradicciones y límites, y una nueva estética, que se revistieron de un significado político ${ }^{27}$. Esta imagen "progre" contribuyó a dar cohesión a la identidad colectiva del movimiento estudiantil. Junto al aspecto melenudo y barbudo de los estudiantes varones, ya analizado en otras investigaciones ${ }^{28}$, habría que incorporar el impacto de la nueva estética en las alumnas. Pilar Aguilar recuerda la liberación que para ella supuso abandonar la falda de tubo, la faja, los tacones y el pelo cardado, por una apariencia más sencilla, que contemplaba el uso de pantalones. Sin embargo, el decano de la facultad de Filosofía y Letras de Sevilla la mandó llamar junto a otras estudiantes para recordarles la conveniencia de vestir falda en la universidad ${ }^{29}$. El deseo de transformar la sociedad y las relaciones personales era una característica de esta juventud estudiantil, en especial la más activa y politizada. Para las mujeres, supuso una notable transgresión no solo en términos políticos, sino también en su vida cotidiana y en las relaciones con sus compañeros ${ }^{30}$.

En suma, acudir a la universidad y participar en las protestas estudiantiles fue una experiencia que implicó un gran impacto emocional, en que el miedo, la esperanza y el deseo de cambiar se superponían. Margarita Gallart,

\footnotetext{
${ }^{26}$ Entrevista a María Gascón, Madrid, 26 de septiembre de 2019.

${ }^{27}$ Kostis Kornetis, "Let's get laid because it's the end of the world': sexuality, gender and the Spanish Left in late Fracoism and the Transición", European Review of History 22, no.1 (2015): 176-198.

${ }^{28}$ Alberto Carrillo-Linares, "Sin corbata y con melena: imágenes y representaciones de los estudiantes sesentayochistas", en Globalizing the student rebellion in the long' 68, ed. Andrés Payá Rico y otros (Salamanca: FarenHouse, 2018), 63-74.

${ }^{29}$ Intervención de Pilar Aguilar en las III Jornadas Educación y Franquismo. Depurados, represaliados y exiliados, 2018 [citado el 20 de diciembre de 2019]: disponible en https:// www.youtube.com/watch?v=uTIIb_AD66o

${ }^{30}$ Mónica Moreno Seco, "Género, transgresión y militancia en la izquierda radical de los años setenta", en Mujeres, dones, mulleres, emakumeak. Estudios sobre la historia de las mujeres y del género, eds. Teresa María Ortega López, Ana Aguado Higón y Elena Hernández Sandoica (Madrid: Cátedra, 2019), 287-301.
} 
estudiante del CEU (Centro de Estudios Universitarios) de Alicante, lo resumía así: "fue una época apasionante para mí, y muy potente, y muy divertida y con mucho miedo, o sea, había muchos sentimientos encontrados" ${ }^{\prime 31}$. En ese sentido, cabe recordar que la movilización juvenil de 1968 fue alentada por un conjunto de emociones, que Giallongo resume en rebelión, antiautoritarismo y aspiración a la felicidad, dando lugar a una comunidad emocional generacional $^{32}$. Además, las mujeres experimentaron a veces indignación ante las prácticas discriminatorias, y alegría al transgredir los límites, lo cual remite a la necesidad de incorporar la perspectiva de género al estudio de las emociones ${ }^{33}$.

\section{Activismo estudiantil}

Las primeras inquietudes de las y los estudiantes solían dirigirse hacia cuestiones poco ambiciosas pero que revelaban un cuestionamiento de la autoridad: "iniciamos una serie de humildes protestas: por la carencia de libros en la biblioteca de la facultad, contra la prohibición de llevar gafas de sol dentro del recinto, por problemas de vestimenta..." ${ }^{34}$. Pronto se convocaron asambleas en las que se empezó a reclamar una mayor participación en el funcionamiento de la universidad. En ocasiones, el interés social y político provenía del contacto o la militancia en organizaciones católicas, como la FECUM, en que militó Margarita Birriel, dirigente estudiantil en la facultad de Filosofía y Letras en Granada ${ }^{35}$.

A mediados de los años sesenta, el movimiento estudiantil se articuló en torno a sindicatos democráticos, alternativos al SEU falangista, que exigían intervenir en la toma de decisiones de los centros universitarios y fueron demandando un cambio político; estaban sustentados por el PCE y otras formaciones más pequeñas, como el FLP o la FUDE. Las mujeres se incorporaron a dichas iniciativas. María Unceta tomó parte en las movilizaciones contra el SEU en Madrid: “¿Qué aprendí en la carrera? Casi nada, pero eso sí,

\footnotetext{
${ }^{31}$ Entrevista a Margarita Gallart por Elías Alonso, Alicante, 3 de octubre de 2018.

${ }^{32}$ Angela Giallongo, "Alcune riflessioni sulle emozioni del Movimento Studentesco: Italia 1968", en Payá Rico, Globalizing, 185-194.

${ }^{33}$ Ludivine Bantigny, "Le genre de l'événement : féminin/masculin en mai-juin 1968 », en Prolétaires de tous les pays, qui lave vos chaussettes? Le genre de l'engagement dans les années 1968, dir. Ludivine Bantigny y otras (Rennes : PUR, 2017), 206-207.

${ }^{34}$ Pilar Aguilar Carrasco, No quise bailar lo que tocaban (Toledo: Almud, 2014), 181.

${ }^{35}$ Javier Contreras-Becerra, "Margarita María Birriel Salcedo. Activismo ciudadano", Andalucía en la Historia 57 (2017): 35-37.
} 
aprendí a liarme. A liarme en el movimiento estudiantil", en las asambleas, el reparto de panfletos y las lecturas políticas ${ }^{36}$. Por las mismas fechas, Empar Pineda llegó a la capital en un momento de grandes protestas "y claro, me meto de cabeza", ingresando en la FUDE. "Entonces el ambiente era una ebullición de que había que acabar con la dictadura, que la íbamos a acabar"; se dedicó a distribuir propaganda, participar en encierros, organizar un homenaje a Bertolt Brecht o un recital de Raimon... "Y no parábamos, si es que no parábamos. Estábamos todo el día, mañana, tarde y noche"37.

Para las mujeres, esta participación en las protestas suponía una presión añadida por el control moral al que estaban sometidas, aunque no todas le concedieron importancia. En un encierro en la facultad de Filosofía y Letras de Sevilla, "recuerdo que algunas chicas alegaban, para votar en contra de mantener la ocupación, que, además [del temor a la represión], pernoctar junto al otro sexo suponía echar a perder para siempre el buen nombre de cualquier mujer"38. En Madrid, en un cartel con una candidatura de estudiantes de la FUDE en 1964, al lado del nombre de Ana Puértolas alguien escribió una serie de insultos sexistas ("puta, zorra, roja"), una reacción que no fue excepcional desde posturas franquistas, que atacaban a las estudiantes más activas con ofensas y alusiones sexuales ${ }^{39}$.

No pocas estudiantes fueron elegidas delegadas de curso o de centro y contribuyeron a la formación de los sindicatos democráticos. Así, en la facultad de Ciencias de Barcelona fue delegada Mariona Petit, quien participó en la Caputxinada de 1966, la sonada reunión fundacional del sindicato en dicho centro universitario, que desencadenó una importante represión ${ }^{40}$. Por su parte, Carmen Romero fue delegada de Filosofía y Letras de Sevilla en el curso 1967-68, estando próxima al PSOE pero sin militar todavía en el mis$\mathrm{mo}^{41}$. Como último ejemplo, integrantes primero de la FUDE y después del PCE de Madrid como Manuela Carmena o Cristina Almeida fueron delegadas de curso en Derecho, además de Francisca Sauquillo, que estaba vinculada a grupos cristianos ${ }^{42}$.

\footnotetext{
${ }^{36}$ Entrevista a María Unceta, Madrid, 27 de septiembre de 2019.

${ }^{37}$ Entrevista a Empar Pineda, SFO (Madrid), 22 de marzo de 2007.

${ }^{38}$ Aguilar Carrasco, No quise, 193.

${ }^{39}$ Entrevista a Empar Pineda, SFO (Madrid), 22 de marzo de 2007. Rodríguez Tejada, “Compañeras", 137-138.

${ }^{40}$ Triunfo, 22 de abril de 1978.

${ }^{41}$ Alberto Carrillo-Linares, Subversivos y malditos en la Universidad de Sevilla (1965-1977) (Sevilla: Fundación Centro de Estudios Andaluces, 2008), 106 y 112.

${ }^{42}$ Irene Díaz, José G. Alén y Rubén Vega, Cristina, Manuela y Paca. Tres vidas cruzadas, entre la justicia y el compromiso (Barcelona: Península, 2017), 95-98.
} 
Las sanciones y el control policial hicieron que muchas acudieran a la universidad de forma esporádica, para organizar protestas y para presentarse a los exámenes, con una dedicación casi total a la militancia. Aunque fue expulsada de la Universidad de Madrid, Empar Pineda seguía acudiendo a reuniones de la FUDE: "no me dejaban entrar, porque ya me conocían todos los grises, y entonces entraba por la parte de atrás, por el bar, y a conspirar, que era lo nuestro"43. Consuelo Catalá, estudiante de Medicina de Valencia, participó en diversas movilizaciones, pero la presión policial hizo que pasara a la clandestinidad y que acudiera a la facultad solo a militar ${ }^{44}$.

Según Mạ Antonia García de León, aunque en términos cuantitativos no había tantas estudiantes, "en 'entrega a la causa', [eran] igual que los chicos" ${ }^{45}$. Como apunta Rodríguez Tejada, las mujeres fueron menos visibles que sus compañeros en el movimiento estudiantil, pues los cargos de poder o de representación solían recaer en varones. No obstante, en ocasiones protagonizaron algunas protestas bastante sonadas, como Carmen Pertejo, que en mayo de 1968 lanzó gritos contra la dictadura en un acto oficial de la Universidad de Valencia, o Marga Pérez, que años después prendió fuego a un retrato de Franco en el mismo centro ${ }^{46}$. En 1967, en la Universidad de Santiago, Adela Rodríguez pronunció delante de las autoridades un discurso crítico en la entrega de diplomas de Químicas ${ }^{47}$. Aunque en sus testimonios insisten en el temor a tomar la palabra en las asambleas, a veces intervenían defendiendo posiciones extremas y exaltadas ${ }^{48}$, lo cual redunda en la complejidad $\mathrm{y}$ heterogeneidad de las identidades de las universitarias antifranquistas.

\section{Militancia en partidos}

La represión desencadenada a partir de finales de los años sesenta influyó en la progresiva politización de las demandas. Como relata Pina López-Gay, "en la Universidad empecé con reivindicaciones meramente académicas. Nos reuníamos para saber si queríamos las clases por la mañana o por la tarde

\footnotetext{
${ }^{43}$ Entrevista a Empar Pineda, SFO (Madrid), 22 de marzo de 2007.

${ }^{44}$ Entrevista a Consuelo Catalá [citada el 16 de diciembre de 2019]: disponible en https:// feministasvalencianas.wordpress.com/consuelo-catala/

${ }^{45}$ García de León, Rebeldes, 59.

${ }^{46}$ Rodríguez Tejada, Zonas de libertad, 190-192.

47 1968. Do "gaudeamus Igitur" ao "Venceremos nós". As mobilizacións estudiantes do 68 en Compostela (Santiago: Fundación 10 de Marzo, 2008), 204.

${ }^{48}$ Carrillo-Linares, Subversivos, 190 y 313.
} 
y siempre acababa llegando la Policía. Entonces me di cuenta de que nos estábamos asfixiando sin libertad" ${ }^{\prime 9}$. Los objetivos se reorientaron hacia un cambio revolucionario y surgieron nuevos repertorios de actuación, entre ellos el recurso a la violencia. En la Universidad de Zaragoza, tres encapuchados, uno de ellos una mujer, agredieron a un profesor de Medicina en 1970, golpeándolo y manchándolo con pintura, lanzando a continuación octavillas de un "partido comunista"50. En Valencia, Cristina Piris intervino en enfrentamientos "amb els fatxes, amb ells a bufetada neta a la facultat"51.

La radicalización de las protestas también se manifestó en que los sindicatos dejaran de ser vistos como una alternativa, lo que dio lugar al aumento de la militancia en partidos. Algunas activas estudiantes se incorporaron al PCE. En Baleares, Lila Thomàs entró en una célula de estudiantes del partido en 1973, cuando empezó la carrera: "montábamos los comités de curso en las facultades. Y bueno, teníamos reuniones preparatorias de los comités de curso, toda esta historia de la clandestinidad." Todavía cursando la carrera, formó parte de la candidatura del PCE en las elecciones de 1977, lo cual supuso un escándalo en su círculo familiar, que era conservador ${ }^{52}$.

En otros casos, las estudiantes ingresaron en los nuevos partidos que estaban surgiendo y en sus organizaciones juveniles, como las Juventudes Universitarias Revolucionarias (JUR), vinculadas al PCE(I), que después darían lugar a la Joven Guardia Roja (JGR), sección juvenil del PTE. En las JUR sevillanas destacaron militantes como Lola Ubera o Pina López-Gay. En Barcelona, Ángela Domínguez renunció a otras actividades (teatro, excursionismo) para centrarse en su militancia en la universidad y sobre todo en la acción política en las JUR y la JGR ${ }^{53}$. Como comenta Llum Quiñonero, estudiante del CEU de Alicante que formó parte del MC, "mi trabajo como estudiante y como militante era organizar cosas dentro de la universidad"54.

Incluso hubo quien participó en la fundación de agrupaciones políticas, como sucedió con María Unceta, Ana Puértolas, Rosa Zurro o Empar Pineda, quienes junto con compañeros varones crearon el Grupo u Organización Lenin en la Universidad de Madrid, que después se fusionaría con otras

${ }^{49} A B C, 23$ de diciembre de 1986.

${ }^{50}$ La Vanguardia, 27 de noviembre de 1970.

${ }^{51}$ Entrevista a Cristina Piris, en Josepa Cucó i Giner, De la utopia revolucionària a l'activisme social. El Moviment Comunista, Revolta i Cristina Piris (Valencia: PUV, 2016), 164.

${ }^{52}$ Entrevista a Lila Thomàs, Palma, 2 de octubre de 2019.

${ }^{53}$ Entrevista a Ángela Domínguez en Archivo de la Transición [citado el 8 de enero de 2020]: disponible en https://www.youtube.com/watch?v=vndexSUPBuA

${ }^{54}$ Entrevista a Llum Quiñonero por Elías Alonso, Alicante, 14 de octubre de 2018. 
agrupaciones para dar lugar al MC ${ }^{55}$. En palabras de Pineda: "Y en el año 69 se nos ocurre, en aquellos tiempos se podía con toda la alegría del mundo y con toda la ingenuidad, fundar un partido, (...) nos planteamos eso, convertirnos en el verdadero partido comunista revolucionario" 56 .

Aunque la mayoría transitó de la movilización estudiantil a la militancia en un partido, hubo quien acudió a las aulas universitarias como parte de su tarea política. Es el caso de Maite Larrauri, en Valencia, quien había abandonado la carrera después de unos meses en París y de emanciparse del hogar familiar, lo que le obligó a buscar trabajo. Seguía en contacto con amigos estudiantes y con un grupo entró en Bandera Roja, cuyos responsables le asignaron la universidad como frente de trabajo político: "volví a la universidad a hacer política", por lo que se matriculó en Filosofía ${ }^{57}$.

De forma paralela, muchas estudiantes, decepcionadas con los estudios e interesadas de manera progresiva por otras actividades, fueron desligándose del movimiento estudiantil. Para Amparo Guardiola, el alejamiento de la militancia universitaria y su sustitución por las protestas obreras y vecinales llegó después de ser expedientada en la Universidad de Valencia ${ }^{58}$. Otras no llegaron a finalizar la carrera, debido a la represión o a una militancia política absorbente. Así, Ma Dolors Calvet se incorporó al PSUC cuando estudiaba en Barcelona, pero decidió dejar la universidad para montar el partido en Hospitalet, su ciudad natal; retomó los estudios siendo diputada en la primera legislatura ${ }^{59}$. Algunas que pertenecían a grupos maoístas se proletarizaron, de manera que comenzaron a trabajar en sectores obreros que el partido deseaba movilizar. También intentaron integrarse en la vida de sus barrios. A veces, esta decisión supuso un coste personal importante, en especial para mujeres jóvenes que habían adoptado costumbre avanzadas, como ha señalado Rodríguez Tejada ${ }^{60}$. Sin embargo, otras veces continuaron con su forma de vida. Cristina Piris, estudiante del MC, vivía en un piso con su compañero y otro chico, pero desde el partido se le instó a casarse, porque la imagen que daba en el barrio no era adecuada para hacer trabajo de masas, aunque ella se negó y logró ser

${ }^{55}$ Entrevista a María Unceta, Madrid, 27 de septiembre de 2019.

${ }^{56}$ Entrevista a Empar Pineda, SFO (Madrid), 22 de marzo de 2007.

${ }^{57}$ Entrevista citada a Maite Larrauri.

${ }^{58}$ Benito Sanz Díaz. L'oposició universitària al franquisme. València, 1939-1975 (Valencia: Universitat de Valencia, 2013), 127.

${ }^{59}$ Entrevista a M ${ }^{\mathrm{a}}$ Dolors Calvet, en Magis Iglesias, Fuimos nosotras. Las primeras parlamentarias de la democracia (Madrid: Debate, 2019).

${ }^{60}$ Rodríguez Tejada, Zonas de libertad, 397-399. 
aceptada por las mujeres del lugar ${ }^{61}$. Al margen de ello, en la clandestinidad o en la participación en saltos y movilizaciones con frecuencia se recurría a una estética moderada, alejaba de la imagen "progre" que solían reproducir, para pasar desapercibidas.

Aunque fue excepcional, algunas estudiantes se convirtieron en cabecillas del movimiento estudiantil y además desempeñaron destacados puestos políticos dentro y fuera de las universidades. Quienes ejercieron algún tipo de liderazgo con frecuencia prolongaron sus estudios o pasaron de una carrera a otra, y en ocasiones siguieron su militancia como profesoras, para asegurar una continuidad política, convirtiéndose en "activistas de larga duración" ${ }^{2}$. Entre las dirigentes, podemos mencionar a Lourdes Ortiz, que llegó a ser responsable de las células del PCE en la Universidad de Madrid en la primera mitad de los años sesenta, o Ángela Domínguez en Barcelona, que se convirtió en secretaria general de la JGR de Cataluña en 1977. Otras líderes carismáticas fueron Pilar Aguilar (JUR) o Amparo Rubiales (PCE) en Sevilla; Olga Quiñones (PCE) en Valencia; o Llum Quiñonero (MC) y Margarita Gallart (ORT) en el CEU de Alicante. En la Universidad de Santiago, Mari Carmen Nieves era conocida por el sobrenombre de Pasionaria ${ }^{63}$.

Dos de ellas llegaron a desempeñar cargos políticos de primer orden en sus partidos: Pilar Brabo y Pina López-Gay. Ambas reflejan las dificultades que debían afrontar las mujeres que irrumpían en espacios de poder y dieron lugar a una serie de imágenes contrapuestas, como las que ellas mismas transmitían como jóvenes fuertes, que los medios de comunicación y su propio entorno reducían en términos de masculinización o hipersexualización ${ }^{64}$. Pilar Brabo fue la principal responsable del PCE en la Universidad de Madrid entre 1967 y 1973, centro donde cursó varias carreras con buenos resultados. En 1968 entró en el Comité Central del partido y dos años después en el Comité Ejecutivo, llegando a ser elegida diputada en 1977 y $1979^{65}$. En las elecciones de 1977, fue saludada por la prensa como una dirigente del partido joven y rubia -es decir, atractiva- y a la vez fumadora compulsiva y distante. Si bien se presentaba como exponente del mundo universitario en el partido, en las entrevistas insistía en su admiración por los líderes del movimiento obrero y por figuras como Dolores Ibárruri, con quien era

\footnotetext{
${ }^{61}$ Entrevista a Cristina Piris, en Cucó, De la utopía, 169.

${ }^{62}$ Álvarez Cobelas, Envenenados, 350-351.

${ }^{63}$ 1968. Do "gaudeamus Igitur", 80.

${ }^{64}$ Mónica Moreno Seco, "Entre la disciplina y la transgresión. Pilar Brabo, dirigente y diputada comunista en la Transición“, Spagna Contemporanea 55 (2019): 83-102.

${ }^{65}$ Álvarez Cobelas, Envenenados, 293.
} 
comparad ${ }^{66}$. Rodríguez Tejada comenta que a pesar de las tensiones entre estas dos culturas políticas, la obrera y la estudiantil, en el PCE se admitía la preponderancia del movimiento obrero; en este sentido interpreta la fidelidad que en numerosas oportunidades Pilar Brabo expresó hacia Carrillo, "subordinando un prestigio personal que cualquier otro partido izquierdista hubiese reportado en un liderazgo propio"67. Una fidelidad que también podría interpretarse en función del género y la edad. No obstante, con el tiempo, Brabo se mostró cada vez más independiente, reconociendo entonces las dificultades que como mujer joven había encontrado en los espacios de dirección del partido. Proyectó una imagen ambigua, que combinó un aspecto juvenil y moderno con un ejercicio decidido del poder y una actitud seria.

Por su parte, Pina López-Gay fue una destacada dirigente estudiantil de la Universidad de Sevilla, donde llegó a ser delegada de la facultad Filosofía y Letras en 1975, además de representante nacional en la Reunión General de Universidades. De forma paralela, ingresó en las JUR al poco de comenzar sus estudios y después en la JGR, organización de la cual fue secretaria general de Andalucía en 1973, siendo nombrada tres años después secretaria general de la JGR española. En 1979 se incorporó al Comité Ejecutivo Federal y al Comité Central del PTE, y se presentó como número dos en la candidatura del partido por Madrid, aunque no obtuvo escaño ${ }^{68}$. Su aspecto físico, del que siempre se destacaba su belleza, estuvo muy presente en su imagen pública. En las entrevistas que concedió, junto a la juventud y el empuje, se preocupó mucho de mostrar la firmeza de sus convicciones ("Me joden las injusticias") y carácter: se definía como exigente y afirmaba que le irritaba la superioridad que a veces mostraban los hombres, mientras en las mujeres le molestaba la pasividad ${ }^{69}$. Las preguntas de los periodistas abordaban su vida privada, algo que no se solía hacer con los dirigentes políticos varones:

- ¿Ligabas mucho?

- Sí, todo lo que podía o me dejaban. ¿Sabes qué pasa? Pues que cuando ocupas puestos de responsabilidad política a veces no eres atractiva por tus encantos físicos. A veces llegaban para ligarse a la delegada del distrito, y cuando fui secretaria general

${ }^{66}$ Pueblo, 14 de enero de 1977.

${ }^{67}$ Sergio Rodríguez Tejada, "Partido comunista y movimiento estudiantil durante el franquismo", en Nosotros los comunistas: memoria, identidad e historia social, eds. Manuel Bueno Lluch y Sergio Gálvez Biesca (Sevilla: FIM-Atrapasueños, 2009), 306.

${ }^{68}$ Alberto Carrillo-Linares, "Josefina López López-Gay", en Mujeres de Andalucía (Sevilla: Junta de Andalucía-Instituto Andaluz de la Mujer, 2001).

${ }^{69}$ Interviú, 8-14 de marzo de 1979. 
de la Joven Guardia, entonces se acercaba hasta gente de derecha por el prurito de ligar con una «roja $»^{70}$.

Esta cita recuerda una vez más que la mirada masculina sobre las universitarias politizadas reproducía estereotipos sexistas. En su Carta abierta a una universitaria, un texto muy leído en aquellos años, el entonces joven profesor de Sociología Amando de Miguel describía en estos términos a las estudiantes más activas, con alusiones a su físico y a su conducta:

en las asambleas libres, juicios críticos y demás hablan los de siempre, por muy espontánea que sea la convocatoria. Siempre actúan los mismos chicos (...). Para que una chica hable tiene que ser de pelo mojado (así lo parece, no sé cómo decirte), con gafitas, sin sujetador (me figuro), tiene que ser ella mucho más radical que los compañeros y debe hablar siempre como cabreada y tembleante ${ }^{71}$.

\section{Una represión sexuada}

Las autoridades académicas y policiales respondieron a esta intensa movilización con una dura represión. Como señala Accornero para el caso portugués, junto a los graves castigos propios de una dictadura (detención, tortura, cárcel), como veremos, también existía una importante represión indirecta (dificultad para finalizar los estudios, obstáculos para encontrar trabajo, etc. $)^{72}$. En el terreno académico, se abrieron numerosos expedientes, como el que por ejemplo afectó en 1972 a 312 estudiantes en la Universidad de Valencia, entre ellos 86 mujeres. Una de las implicadas fue Amparo Guardiola, para quien la sanción supuso tener que presentarse por libre a los exámenes, perder su trabajo y no conseguir el certificado de buena conducta imprescindible para superar las oposiciones ${ }^{73}$.

Los expedientes se tradujeron en apercibimientos y en expulsiones temporales o definitivas del distrito universitario. A Cristina Piris se le prohibió asistir a clase en Salamanca y se le impuso la obligación de residir en su hogar paterno en Santander, desde donde acudía a la ciudad castellana solo a realizar los exámenes ${ }^{74}$. En el CEU alicantino lo mismo le sucedió a Margarita Gallart, a quien además se le retiró el pasaporte, lo cual le impidió salir al extranjero a

\footnotetext{
${ }^{70} A B C, 23$ de diciembre de 1986.

${ }^{71}$ Amando de Miguel, Carta abierta a una universitaria (Madrid: Ediciones 99, 1973), 30-31.

${ }^{72}$ Guya Accornero, The revolution before the revolution: late authoritarianism and student protest in Portugal (New York-Oxford: Berghahn Books, 2016), 7.

${ }^{73}$ Sanz Díaz, L'oposició, 122-127.

${ }^{74}$ Entrevista a Cristina Piris, en Cucó, De la utopía, p. 163.
} 
estudiar "como era mi proyecto. Fue para mí durísimo"75. Sin embargo, Llum Quiñonero vivió la expulsión temporal como una época de mayor libertad de movimientos, para asistir a las clases que quería o para ir al bar a conspirar ${ }^{76}$. Las expulsiones definitivas significaban el traslado a otros centros universitarios. Manuela Carmena tuvo que terminar la carrera en Valencia, después de participar en un encierro ${ }^{77}$. En algunas ocasiones este cambio fue percibido como un enriquecimiento, por el contacto con profesores abiertos y modernos, como interpretaron estudiantes sevillanas que se desplazaron a Barcelona, como Carmen Hermosín o Lola Ubera ${ }^{78}$. En otras, sin embargo, al cambiar a universidades pequeñas y tradicionales, la actividad política se vio dificultada. Empar Pineda fue expedientada por acudir a una protesta contra la guerra de Vietnam, lo que le obligó a dejar Madrid para matricularse en Salamanca y más tarde en Oviedo, aunque siguió militando en la capital ${ }^{79}$. Por último, los traslados también permitieron contactos entre grupos politizados y la reactivación de algunos de ellos, como hizo a principios de los años setenta Isabel Kéller, procedente de Madrid, con el PCE en la Universidad de Sevilla ${ }^{80}$.

Más grave fue la represión desencadenada por la policía, que se tradujo en detenciones, maltrato, multas y encarcelamiento. Todas quienes pasaron por comisaría recuerdan el miedo y la presión a la que fueron sometidas, además de la suciedad, la falta de intimidad y el ambiente sórdido de los locales policiales. La mayoría insiste en que sus compañeros varones fueron golpeados con dureza, mientras a ellas se les dispensó un trato menos violento. María Unceta recuerda:

pues estuvimos como una semana o así en comisaría, diez días quizá. Bueno, interrogatorio va, interrogatorio viene, a mí no me tocaron. A mis... a algunos de mis compañeros sí. A las chicas a ninguna." [Pero] "independientemente de que a mí no me maltrataran, pasabas miedo de que te pudiera pasar lo [que a otros]. Y luego, oíamos unas cosas, los lamentos, los gritos ${ }^{81}$.

No obstante, hay quien resta importancia a la violencia experimentada, aunque constituyera un daño serio ${ }^{82}$. No se alude a agresiones sexuales,

\footnotetext{
${ }^{75}$ Entrevista a Margarita Gallart por Elías Alonso, Alicante, 3 de octubre de 2018.

${ }^{76}$ Entrevista a Llum Quiñonero por Elías Alonso, Alicante, 14 de octubre de 2018.

${ }^{77}$ Díaz, Alén y Vega, Cristina, Manuela y Paca, 106.

${ }^{78}$ Carrillo-Linares, Subversivos, 318.

${ }^{79}$ Entrevista a Empar Pineda, SFO (Madrid), 22 de marzo de 2007.

${ }^{80}$ Carrillo-Linares, Subversivos, 339-340.

${ }^{81}$ Entrevista a María Unceta, Madrid, 27 de septiembre de 2019.

${ }^{82}$ Como el que sufrió Pilar Aguilar (No quise, 88).
} 
aunque sí se recuerdan las amenazas. Se han ofrecido dos interpretaciones sobre el tratamiento diferenciado que recibieron las universitarias por parte de la policía y de las autoridades. En primer lugar, pertenecían a familias acomodadas, a veces bien relacionadas por el régimen, lo que les proporcionó una protección especial. Fue el caso por ejemplo de Pina López-Gay, cuyo padre era el secretario del gobierno civil de Sevilla ${ }^{83}$.

En segundo lugar, la policía actuaba influida por estereotipos sexistas, que reproducían una imagen poco politizada de las jóvenes, a quienes no se consideraba responsables de las protestas ${ }^{84}$. Amparo Ferrando recuerda que la policía de Valencia solía pensar que eran las novias de los dirigentes, por lo que las sometía a una menor vigilancia o actuaban con ellas con menos crueldad ${ }^{85}$. Según Pilar Aguilar, los agentes que la interrogaron preferían pegar a hombres: "en este caso el machismo jugaba a mi favor" ${ }^{\text {"86 }}$. Dicha imagen les permitía, en la clandestinidad, distribuir propaganda de forma poco sospechosa, aunque también estaban sometidas a un gran control social, que dificultada sus tareas políticas.

Sin embargo, los estereotipos podían agravar la presión sobre ellas. Según la alicantina Margarita Gallart, cuando fue detenida a su familia le impactó mucho la acusación de que "me habían encontrado además en la cama en plena orgía con 20.000 comunistas que me estaban violando y que yo me dejaba y consentía porque era una roja"87. Los informes policiales revelan que el paternalismo fue dando paso, a finales de los años sesenta, a un incremento de las torturas, de una imagen más peligrosa de las estudiantes y de los juicios sobre su conducta moral, todo lo cual confirma a juicio de Varo que pueda hablarse de una represión sexuada ${ }^{88}$.

\footnotetext{
${ }^{83}$ Carrillo-Linares, Subversivos, 318.

${ }^{84}$ Rodríguez Tejada, Zonas de libertad, 360-361 y 385. Sin embargo, en Grecia, la policía se caracterizó por su misoginia y por el duro trato dispensado a las estudiantes, con casos de acoso sexual y violencia psicológica, según Kostis Kornetis, Children of the dictatorship. Student Resistance, Cultural Politics and the 'Long 1960s' in Greece (New York-Oxford: Berhahn Books, 2013), 210 y 242.

${ }^{85}$ Entrevista a Amparo Ferrando [citado el 17 de diciembre de 2019]: disponible en https://feministasvalencianas.wordpress.com/amparo-ferrando/

${ }^{86}$ Aguilar Carrasco, No quise, 230.

${ }^{87}$ Entrevista a Margarita Gallart por Elías Alonso, Alicante, 3 de octubre de 2018. En Portugal también se utilizaron prejuicios morales contra las estudiantes, según Accornero, The revolution, 115.

${ }^{88}$ Nadia Varo Moral, "Mujeres y hombres: la 'represión sexuada' de la militancia política", en Resistencia ordinaria. La militancia y el antifranquismo catalán ante el Tribunal de Orden Público (1963-1977), ed. Javier Tébar Hurtado (Valencia: PUV, 2012), 96-99.
} 
Muchas de estas universitarias fueron juzgadas y condenadas. Por ejemplo, en 1962, Anna Sallés, estudiante de Filosofía y Letras de Barcelona y militante del PSUC, fue sancionada a seis meses de prisión por promover una manifestación en solidaridad con los mineros de Asturias ${ }^{89}$. Unos años después, en 1968, Ma Ángeles Marza y Rosa Zurro fueron condenadas a dos años de prisión y multa por leer unos textos de comisiones de obreros y de estudiantes en una asamblea celebrada en la facultad de Filosofía y Letras de Madrid ${ }^{90}$. En un estudio realizado sobre personas procesadas por el TOP (Tribunal de Orden Público) en Cataluña, destaca el porcentaje de universitarias dentro del colectivo de las mujeres, con una proporción mayor que entre los hombres ${ }^{91}$. No obstante, era frecuente que recibieran penas menores; así, en 1969, mientras varios compañeros fueron confinados en distintos lugares del país o encarcelados, algunas dirigentes estudiantiles sevillanas quedaron bajo arresto domiciliario ${ }^{92}$.

Por otro lado, algunas líderes estudiantiles muy politizadas tuvieron que emprender el camino del exilio, en especial a Francia, como hicieron Rosa Zurro (MC) y Pilar Aguilar (PTE). Hubo casos especialmente dramáticos, como el de Lola González Ruiz, integrante del FLP de Madrid, detenida en 1969 junto con su novio Enrique Ruano, asesinado por la policía días después del arresto $^{93}$. En enero de 1977, la estudiante de la facultad de Ciencias Políticas y Sociología de la Universidad Complutense, Mari Luz Nájera, murió en una manifestación, al ser golpeada en la cabeza por un bote de humo lanzado por la policía ${ }^{94}$.

No obstante, la represión tuvo consecuencias paradójicas, pues si bien muchas veces pudo resultar disuasoria, con frecuencia y a medida que avanzaba la época estudiada impulsó a una militancia cada vez más radicaliza$\mathrm{da}^{95}$. Concha Gisbert, estudiante de Derecho en Valencia, recuerda:

a mí en una manifestación del uno de mayo me detienen, y entonces hay una diferencia entre el antes y el después de eso. Antes, pues era como que participas porque todo el mundo participa (...). Pero a partir de ese momento sí que fue como si mis

${ }^{89}$ Mary Nash, Dones en transició (Barcelona: Ajuntament de Barcelona, 2007), 54.

${ }^{90}$ La Vanguardia, 17 de octubre de 1968.

${ }^{91}$ Varo Moral, "Mujeres y hombres", 88-89.

${ }^{92}$ Carrillo-Linares, Subversivos, 201.

${ }^{93}$ Y cuya segunda pareja, Javier Sauquillo, murió en el atentado contra el despacho de abogados laboralistas de Atocha en 1977. Remitimos a Javier Padilla, A finales de enero. La historia de amor más trágica de la Transición (Barcelona: Tusquets, 2019).

${ }^{94}$ El País, 25 de enero de 1977.

${ }^{95}$ Accornero, The revolution, 7-8. 
relaciones con todo ese mundo cambiaran un poco, porque la gente, bueno, era un poco de gloria que te hubieran detenido, que te juzgaran en el TOP, todo eso. Y yo no tuve una reacción de decir ya no me meto en nada, y entonces a partir de ese momento empecé a tener contacto con ese movimiento que era estudiantil, pero además tenía otros contactos [con la LCR $]^{96}$.

Algo parecido relata Llum Quiñonero, detenida en Alicante por sus actividades reivindicativas en el CEU en demanda de mejores servicios para el campus. Ese arresto fue su bautismo político: "En realidad me envalentonó aquel comportamiento tan desmedido, lejos de asustarme me convirtió en una militante de verdad". Además, el director del CEU la expulsó acusándola de comunista, "mi padre me dijo que yo era una delincuente pública y yo me quedé muy preocupada y muy interesada por qué era el comunismo", ingresando poco después en el $\mathrm{MC}^{97}$.

\section{Entre la igualdad y la discriminación}

Cuando entraban en las aulas universitarias, las estudiantes debían sortear los prejuicios que alumnos y profesores tenían sobre ellas, a quienes se atribuía por ejemplo un exclusivo interés en encontrar marido. Mariona Petit, estudiante de Matemáticas de Barcelona, recuerda los comentarios sobre su supuesta incapacidad para encontrar trabajo o sobre su aspecto físico ${ }^{98}$. En la facultad de Derecho de Valencia, Carmen Alborch tuvo que afrontar sospechas sobre su valía intelectual, el paternalismo que le pretendía proteger de cuestiones consideradas inmorales o la atención explícita a su apariencia, aunque entre compañeros progresistas las actitudes solían ser más respetuosas ${ }^{99}$.

La movilización universitaria era percibida como un espacio igualitario o al menos más horizontal que otros. Así lo describen algunas militantes del PCE de los años sesenta, como Lourdes Ortiz: "Juntos tomábamos las decisiones, juntos discutíamos de los más diversos temas durante horas y horas, juntos estudiábamos y combatíamos"100. En los mismos términos se expresa-

\footnotetext{
${ }^{96}$ Entrevista a Concha Gisbert, SFO (Madrid), 12 de abril de 2007.

${ }^{97}$ Entrevista a Llun Quiñonero por Elías Alonso, Alicante, 14 de octubre de 2018.

${ }^{98}$ Triunfo, 22 de abril de 1978.

${ }^{99}$ Entrevista a Carmen Alborch [citada el 17 de diciembre de 2019]: disponible en https:// feministasvalencianas.wordpress.com/carmen-alborch/

${ }^{100}$ Testimonio de Lourdes Ortiz, en Julia Varela Fernández, Pilar Parra Contreras y Alejandra Val Cubero, Memorias para hacer camino: relatos de vida de once mujeres españolas de la generación del 68 (Madrid: Morata, 2016).
} 
ba Pilar Brabo: "Nunca he notado discriminaciones hacia mí. Obedece, pienso, a que he militado en la Universidad, en que el papel de la mujer es más comprendido"101. Ambas admiten que en el partido podían existir actitudes machistas entre los compañeros, pero no en las células de la universidad. En términos generales, quienes ejercieron un liderazgo en las movilizaciones y en sus organizaciones no percibieron un trato injusto. Empar Pineda (MC) insiste en que no se sintió discriminada, sino por el contrario más bien recono$\mathrm{cida}^{102}$. Manuela Carmena recuerda que respiraba una sensación de igualdad, sin embargo Cristina Almeida es más crítica con el paternalismo con el que las trataban los compañeros ${ }^{103}$. La estudiante de Derecho de Valencia Amparo Ferrando insiste en que dentro del PCE el prestigio de los obreros suponía que se valorara poco a los estudiantes y menos incluso a las universitarias, testimonio que plantea de nuevo la intersección entre género, clase y edad ${ }^{104}$.

En ese sentido, muchas reconocen sus dificultades para intervenir en las asambleas y las reuniones, sus dudas para plantear cuestiones teóricas o sus temores al asumir puestos de responsabilidad, frente al predominio que solían ejercer los varones. La inseguridad en que habían sido formadas o el control familiar sobre los horarios y las compañías que frecuentaban representaban obstáculos añadidos para las mujeres. A veces se rebelaron contra esta situación. Pero otras admiten que no eran conscientes de la misma o que la aceptaban precisamente por la educación recibida ${ }^{105}$. Según María Unceta,

tampoco notábamos nosotras que se nos tratara ni más ni menos. Yo sí que creo que tenía un poco interiorizado lo de que ellos saben más, ¿eh?, eso sí. (...) que ellos saben más y que a ellos hay que escucharles más y que ellos... Desde luego, tomaban la palabra más ${ }^{106}$.

Las nuevas costumbres que iban extendiéndose en los ambientes universitarios permitieron unas relaciones personales y sexuales menos encorsetadas, a lo que contribuyeron lecturas de textos como El segundo sexo de Simone de Beauvoir o La revolución sexual de Wilhelm Reich. No obstante, hubo casos de embarazos que condujeron a matrimonios precipitados o a

101 Pueblo, 14 de enero de 1977.

${ }^{102}$ Entrevista a Empar Pineda en "Terrícoles", 2019 [citada el 15 de enero de 2020]: disponible en https://www.youtube.com/watch?v=0UukxzyReCs

${ }^{103}$ Díaz, Alén y Vega, Cristina, Manuela y Paca, 110.

${ }^{104}$ Entrevista citada a Amparo Ferrando.

${ }^{105}$ Idea en la que insiste Rodríguez Tejada, “Compañeras”, 139.

${ }^{106}$ Entrevista a María Unceta, Madrid, 27 de septiembre de 2019. 
abortos clandestinos ${ }^{107}$. Por otro lado, la revolución sexual de aquellos años muchas veces se vivió en términos liberadores, se disfrutó "de forma gozosa y sin complejos ni miedos [de] la sexualidad" ${ }^{108}$. Pero en ocasiones las mujeres se sintieron presionadas para aceptar relaciones sexuales no deseadas. Mariona Petit afirma que en el movimiento estudiantil hubo dos épocas, antes y después de 1968:

a) La época en que todos éramos compañeros que hacíamos la revolución. Aparentemente no había sexos. Todos éramos puros. Eran tiempos místicos.

b) La época de la liberación sexual. Si luchábamos contra toda represión había que luchar también contra la represión sexual.

Una liberación artificial, que se concretaba fundamentalmente en ligar y, sobre todo por parte de los tíos, en explicarlo después. Había tíos que iban incluso con listas. Y se hacían comentarios de lo más grosero, con pocas pruebas de afectividad y de sensibilidad.

Petit piensa que fue "una liberación sexual a la medida de los hombres"109. Para Carmen Alborch "había aquella historia de que 'compañera, si eres progre aquí todos nos relacionamos sexualmente', [y ella contestaba] 'oye, no, precisamente tengo mi libertad, y puedo decir que sí o puedo decir que no'”'110. De manera que no siempre aceptaron esa presión.

Como puede comprobarse, en el imaginario colectivo de muchos estudiantes las relaciones con las mujeres eran un aliciente más de la militancia y a veces "éramos héroes y el ser héroe tiene como recompensa llevarse a la más bella y cosas así"111. El sexismo pervivía también en las críticas a las profesoras desde algunos grupos estudiantiles radicales, como se observa en un anónimo distribuido en la Universidad de Valencia, con críticas a un docente y "sus zorras" (ayudantes) ${ }^{112}$.

Esta pluralidad de realidades y la convivencia de actitudes contradictorias entre mujeres y hombres se reprodujeron en otros contextos, como el griego, donde en algunos círculos se discutía sobre la experimentación se-

${ }^{107}$ Rodríguez Tejada, “Compañeras”, 144. Álvarez Cobelas, Envenenados, 352.

108 Testimonio de Lourdes Ortiz en Varela, Parra y Val, Memorias.

${ }^{109}$ Triunfo, 22 de abril de 1978.

${ }^{110}$ Entrevista citada a Carmen Alborch.

${ }^{111}$ Cit. en Álvarez Cobelas, Envenenados, 196. También en Grecia una vida sexual activa reforzaba la imagen de los líderes varones: Nikolaos Papadogiannis, "Confronting 'Imperialism' and 'loneliness': Sexual and gender relations among young Communists in Greece, 19741981", Journal of Modern Greek Studies 29, no. 2 (2011): 219-250.

${ }^{112}$ Rodríguez Tejada, Zonas de libertad, 284. 
xual, pero en otros pervivía incuestionada la figura del matrimonio ${ }^{113}$. Como señala Batigny, las paradojas del mayo del 68 se observan con claridad en las relaciones de género, por el sexismo en las representaciones, la división sexual de las tareas y la pervivencia de la doble moral entre estudiantes ${ }^{114}$.

\section{Incorporación al feminismo}

La experiencia de la discriminación, las lecturas críticas y las reuniones donde compartían emociones comunes fueron forjando el interés de estas inquietas estudiantes por el feminismo ${ }^{115}$. Aunque se ha afirmado que para la mayoría de las universitarias la conciencia feminista no surgió cuando participaban en el movimiento estudiantil, sino que se desarrolló en la militancia posterior o a partir de vivencias de la vida adulta como la maternidad ${ }^{116}$, habría que insistir en la heterogeneidad que muestran los testimonios. Algunas se aproximaron al movimiento feminista mientras cursaban la carrera, otras lo hicieron una vez que abandonaron las aulas.

A mediados de los años sesenta, Cristina Almeida, Manuela Carmena y Francisca Sauquillo participaron en Madrid en encuentros donde comentaban libros feministas de referencia. En palabras de Sauquillo:

Yo recuerdo que ya en segundo de Derecho, pues organizamos un seminario también sobre el tema de la mujer. En aquel momento empezaban a salir libros, por un lado de Simone Beauvoir, El segundo sexo, La mística de la feminidad, de Betty Friedan. Entonces aquello para nosotras, aquello era como el no había [va] más. Nos reuníamos en un seminario, allí en la universidad, a leer el libro juntas y luego a comentarlo ${ }^{117}$.

Las dos primeras, siendo aún estudiantes, participaron en un conocido número especial de Cuadernos para el Diálogo sobre la situación de las mujeres en 1965, con sendos artículos en defensa de unas relaciones igualitarias entre hombres y mujeres ${ }^{118}$. Una experiencia parecida tuvo Llum Quiñone-

${ }^{113}$ Kornetis, Children, 208-211.

${ }^{114}$ Bantigny, "Le genre”, 199-212. También Sara M.Evans, "Sons, Daughters and Patriarchy. Gender and the 1968 Generation", American Historical Review 114 (2009): 331-347.

${ }^{115}$ Sobre la importancia de las emociones en el desarrollo de una identidad colectiva feminista, Mercedes Arabaiza Villalonga, "Dones en transició: el feminismo como acontecimiento emocional", en Mujeres, dones, mulleres, 267-286.

${ }^{116}$ Rodríguez Tejada, "Compañeras", 146.

${ }^{117}$ Entrevista a Francisca Sauquillo, Madrid, 29 de junio de 2015.

${ }^{118}$ Díaz, Alén y Vega, Cristina, Manuela y Paca, 114-115. 
ro unos años después, pues mientras se movilizaba en el campus al mismo tiempo se interesaba por numerosas cuestiones, desde el marxismo al Tercer Mundo, la sexualidad o los derechos de las mujeres ${ }^{119}$. Por las mismas fechas, en Valencia, Asunción Ventura recuerda que ella y sus compañeras sentían incomodidad ante el trato discriminatorio recibido, también en las agrupaciones de izquierda, lo que les animó a crear un grupo en la facultad de Derecho donde discutían sobre feminismo ${ }^{120}$.

Sin embargo, otras como Empar Pineda reconocen que no descubrieron el feminismo hasta años después de dejar el claustro universitario ${ }^{121}$. Muchas insisten en que las demandas feministas estaban muy poco presentes en el movimiento estudiantil, por la urgencia de la acción antifranquis$\mathrm{ta}^{122}$, así que parece que el interés, cuando existió, obedeció a inquietudes personales o de círculos de mujeres. Por tanto, al igual que en Portugal o en Grecia, no se llegó a elaborar un discurso feminista en el seno del movimiento universitario ${ }^{123}$. Sin embargo, a diferencia de estos dos países, no puede olvidarse que en fechas tempranas surgieron asociaciones feministas en que las universitarias estaban muy presentes; además hubo grupos compuestos de manera mayoritaria por ellas.

Una organización con larga tradición fue la Asociación Española de Mujeres Universitarias (AEMU o AMU), que en el franquismo era un espacio de debate para mujeres con estudios universitarios vinculadas a la cultura republicana. En 1970, ante la falta de contacto con las jóvenes estudiantes del momento, se decidió renovar la dirección con Natacha Seseña como presidenta. A partir de entonces la AEMU empezó a organizar cursos y seminarios sobre las condiciones de vida de las mujeres. Tres años después le sucedió en el cargo Jimena Alonso, quien confirió una fuerte impronta feminista a la asociación, convertida en una plataforma para crear el Frente para la Liberación de la Mujer en 1976, con destacada presencia de docentes universitarias. Bajo la presidencia de Alonso, profesora de Árabe de la Universidad Complutense, se incorporaron activistas jóvenes a la AMU y se convocaron numerosos actos feministas, hecho que supuso la suspensión de actividades durante tres meses por decisión gubernativa. Además, la asociación participó en la organización de las I Jornadas de Liberación de la Mujer

\footnotetext{
${ }^{119}$ Entrevista a Llum Quiñonero por Elías Alonso, Alicante, 14 de octubre de 2018.

${ }^{120}$ Entrevista citada a Asunción Ventura.

${ }^{121}$ Entrevista a Empar Pineda, SFO (Madrid), 22 de marzo de 2007.

${ }^{122}$ Entrevista a Olga Quiñones, en Sanz Díaz, L'oposició, 78-79.

${ }^{123}$ M. Cardina, "Olhares sobre uma ausência: O movimento estudantil no Estado Novo e o feminismo", Latitudes-Cahiers Lusophones 34 (2009): 38-42. Kornetis, Children, 212.
} 
de diciembre de 1975, que dieron un destacado impulso al movimiento feminista español ${ }^{124}$.

Con el apoyo de la AMU de Madrid, surgieron o se revitalizaron agrupaciones en otros lugares. En Barcelona ya existía una sede, con la que colaboraba Irene Falcón, pero que tenía poca actividad. Mํㅡㄹ Dolors Calvet y otras compañeras del PSUC decidieron dinamizarla en 1974-1975 para obtener una cobertura legal desde la cual defender los derechos de las mujeres. Con militantes de diferentes procedencias, la AMU de Barcelona participó en la coordinación de las Jornades Catalanes de la Dona de mayo de 1976, hito fundamental en la consolidación del feminismo español. En este encuentro, la AMU presentó además una ponencia sobre la sexualidad femenina y propuso la despenalización del aborto ${ }^{125}$.

A finales de 1975 se creó en Valencia la asociación Mujeres Universitarias, como delegación de la AMU de Madrid, que le dio soporte legal. Aunque en su junta directiva destacaron militantes del PCE como Olga Quiñones o feministas vinculadas al MDM (Movimiento Democrático de Mujeres, vinculado al partido comunista), fue un espacio de debate y reflexión muy plural, en el que también intervinieron Trini Simó, Carmen Alborch, Maite Larrauri, Concha Gisbert o Margarita y Dolores Sánchez, entre muchas otras. En su presentación pública en marzo de 1976, se indicó que estaba compuesta por estudiantes de distintas disciplinas; no obstante, además de alumnas pertenecían a la misma profesoras universitarias y de enseñanza media, muchas de las cuales habían sido activistas del movimiento estudiantil en los años previos ${ }^{126}$.

En Sevilla, el PCE impulsó la AUM (Asociación Universitaria de Mujeres), con la participación de dirigentes estudiantiles como la comunista Clotilde Ríos. Dada a conocer en septiembre de 1976, en su propaganda afirmaba:

Esta asociación nace con el fin de organizar a todas las universitarias para la consecución de todos los derechos que como mujeres nos pertenecen, y que en la ac-

${ }^{124}$ Ma Luisa Maillard, Asociación Española de Mujeres Universitarias (1920-1990) (Madrid: Instituto de la Mujer, 1990), 90-101 y 102-107. Natacha Seseña, "AEMU (1920-1990). Setenta años de labor seria y libre a favor de la mujer", en El movimiento feminista en España en los años 70, eds. Carmen Martínez Ten, Purificación Gutiérrez López y Pilar González Ruiz (Madrid: Cátedra, 2009), 377-383. Testimonio de Jimena Alonso en Varela, Parra y Val, Memorias.

${ }^{125}$ Nash, Dones en transició, 97-98 y 128-130.

${ }^{126}$ Agradezco la información facilitada por Dolores Sánchez Durá. También Vicenta Verdugo, "Mujeres jóvenes en la Transición Democrática: la Coordinadora y la Asamblea de Mujeres de Valencia", Historia Contemporánea 54 (2017): 96. Entrevista a Trini Simó y Olga Quiñones [citada el 17 de diciembre de 2019]: disponible en https://feministasvalencianas.wordpress. com/trinidad-simo-y-olga-quinones/ 
tualidad nos son negados en España. Nuestro objetivo no es luchar por problemas estudiantiles, sino por problemas feministas; podemos decir que la asociación está compuesta por universitarias, pero planteamos la problemática global de la mujer ${ }^{127}$.

Por otra parte, por iniciativa de unas estudiantes de la Universidad Complutense, se creó en 1976 la Asociación Universitaria para el Estudio de los Problemas de la Mujer (AUPEPM). Interesada por cuestiones generales y también por la situación de las mujeres en la universidad y en el movimiento estudiantil, organizó el Día de la Mujer Universitaria, además de numerosas conferencias y seminarios. En abril de 1976, la AUPEPM declaraba que sus fines eran el análisis y denuncia de la discriminación de las mujeres. Sobre la universidad reclamaba:

- Hacer que los estudiantes superen los condicionamientos educacionales discriminatorios con que llegan a la Universidad.

- Incorporación de la mujer a la lucha por sus reivindicaciones específicas.

- Participación activa de la mujer en la vida universitaria ${ }^{128}$.

Entre las filas de la AUPEPM de Madrid figuraban estudiantes como Justa Montero, que empezó a estudiar Económicas a principios de la década de los setenta y se implicó en las protestas estudiantiles, en la LCR y en el feminismo ${ }^{129}$. Por su parte, el PTE promovió la aparición de asociaciones denominadas también AUPEPM, presentes en numerosas ciudades, cuyo objetivo era integrar a todas las universitarias en la movilización feminista. Esta iniciativa fue rechazada por la AUPEPM de Madrid, que deseaba ser autónoma de los partidos, criticando el intento del PTE controlarla ${ }^{130}$.

En los años setenta, a medida que el feminismo cobró fuerza, se multiplicaron los grupos de mujeres universitarias. Como recoge Augustín, existían secciones de AMU y AUPEPM en Sevilla y Granada, de AUPEPM en Cádiz y Málaga, Grups de Dones d'Universitat en Barcelona, un Movimiento Universitario para la Liberación de la Mujer en Valladolid y un Grupo de Mujeres de la Universidad de La Laguna. Además, numerosas activistas estudiantiles participaron en diversas asociaciones feministas y en la década siguiente

${ }^{127}$ Carrillo-Linares, Subversivos, 576.

${ }^{128}$ Ciudadano. Dossier, no. 4, abril de 1976.

${ }^{129}$ Entrevista a Justa Montero, SFO (Madrid), sf.

${ }^{130}$ Mercedes Augustín Puerta, Feminismo: identidad personal y lucha colectiva. Análisis del movimiento feminista español en los años 1975 a 1985 (Granada: Universidad de Granada, 2003), 98-100. 
promovieron la fundación de centros de estudios de las mujeres, ya como profesoras universitarias ${ }^{131}$.

\section{Conclusiones}

En los años sesenta y primeros setenta, la llegada de numerosas jóvenes a las aulas universitarias y su implicación en las movilizaciones que sacudieron los claustros tuvieron destacadas repercusiones. Por un lado, muchas adoptaron nuevas costumbres y afrontaron las relaciones personales en términos más horizontales, lo que dio lugar a la construcción de subjetividades rebeldes, propias de la ruptura generacional del momento, pero que con ellas adoptó un cariz específico, no exento de contradicciones. En segundo término, la movilización estudiantil permitió un inédito aprendizaje político y una vía de entrada a la oposición antifranquista, en un ámbito en que la presencia de mujeres era notable. Aunque su visibilidad fuera menor, incidieron en el funcionamiento de las organizaciones estudiantiles, si bien no las convirtieron en espacios igualitarios. A medida que se fueron incorporando a la militancia estudiantil y antifranquista, contribuyeron a normalizar unas relaciones algo más equilibradas. No obstante, pervivieron distintas actitudes discriminatorias, lo que quebró la apariencia de igualdad que proyectaba el mundo universitario. Por tanto, la heterogeneidad en las relaciones de género fue la norma. Además, el interés por el feminismo surgió a veces durante la etapa estudiantil, aunque fue también frecuente que apareciera una vez terminada la carrera. Si bien el movimiento estudiantil no llegó a incorporar una agenda abiertamente feminista en los años estudiados, pues cuando los partidos de izquierda lo hicieron, ya entrados los setenta, las universidades habían perdido importancia en la acción política, no puede olvidarse que la experiencia del activismo sirvió a muchas jóvenes para dar impulso a asociaciones feministas, algunas vinculadas directamente a la universidad.

La intersección entre género, edad y clase ha permitido reflexionar sobre la especificidad de las universitarias, como mujeres jóvenes de clase media, y sobre sus representaciones. Han desfilado por estas páginas estudiantes que abandonaron las faldas para asumir una estética y un comportamiento transgresores, que no siempre alzaban su voz en las asambleas pero que aceptaban riesgos en tareas clandestinas. Jóvenes que provenían

${ }^{131}$ Augustín Puerta, Feminismo, 101. 
de ambientes privilegiados pero admiraban a la clase trabajadora, que en ocasiones no valoraba su activismo. Mujeres que fueron definidas por la policía y los medios de comunicación en términos paternalistas, despectivos y sexualizados, pero que se entregaron a la militancia con la misma pasión que sus compañeros, y que cometieron los mismos errores. Activistas que encontraron camaradas varones con quienes compartir ideales y emociones, y se debatieron entre la resignación y la indignación ante la continuidad de las actitudes jerarquizadas en los círculos de izquierda. En suma, diferentes realidades, imágenes contradictorias e identidades conflictivas que definieron a aquellas universitarias que participaron en el desgaste del franquismo y contribuyeron a la llegada de la democracia a nuestro país.

\section{Bibliografía}

1968. Do "gaudeamus Igitur" ao "Venceremos nós". As mobilizacións estudiantes do 68 en Compostela. Santiago: Fundación 10 de Marzo, 2008.

ACCORNERO, GUYA. The revolution before the revolution: late authoritarianism and student protest in Portugal. New York-Oxford: Berghahn Books, 2016.

Aguilar Carrasco, Pilar. No quise bailar lo que tocaban. Toledo: Almud, 2014. ÁLVAREZ Cobelas, José. Envenenados de cuerpo y alma. La oposición universitaria al franquismo en Madrid (1939-1970). Madrid: Siglo XXI, 2004.

Arabaiza Villalonga, Mercedes. "Dones en transició: el feminismo como acontecimiento emocional". En Mujeres, dones, mulleres, emakumeak. Estudios sobre la historia de las mujeres y del género, editado por Teresa María Ortega López, Ana Aguado Higón y Elena Hernández Sandoica. Madrid: Cátedra, 2019.

Augustín Puerta, Mercedes. Feminismo: identidad personal y lucha colectiva. Análisis del movimiento feminista español en los años 1975 a 1985. Granada: Universidad de Granada, 2003.

BANTIGNY, LUdivine. "Le genre de l'événement : féminin/masculin en maijuin 1968". En Prolétaires de tous les pays, qui lave vos chaussettes? Le genre de l'engagement dans les années 1968, dirigido por Ludivine Bantigny y otras. Rennes: PUR, 2017.

BERGÈs, KARINE Y MERCEDES YuSTA RodRIGO. "Introduction. Femmes et politique, le genre et l'engagement”. En Résistantes, militantes, citoyennes. L'engagement politique des femmes aux xxe et xxie siècles, dirigido por Karine Bergès y otras. Rennes: PUR, 2015. 
CARbajo Vázquez, Judith. “Mujeres y educación (1965-1975)”. En Historia de las mujeres en España. Siglo XX, dirigido por Josefina Cuesta Bustillo, vol. II. Madrid: Instituto de la Mujer, 2003.

CARDINA, M. "Olhares sobre uma ausência: 0 movimento estudantil no Estado Novo e o feminismo". Latitudes-Cahiers Lusophones, 34 (2009): 38-42.

CARrillo-Linares, Alberto. "Josefina López López-Gay". En Mujeres de Andalucía, Sevilla: Junta de Andalucía-Instituto Andaluz de la Mujer, 2001.

CARrillo-Linares, AlBerto. "Movimiento estudiantil antifranquista, cultura política y transición a la democracia”. Pasado y Memoria. Revista de Historia Contemporánea, 5 (2006): 149-170.

CARRILlo-Linares, AlBerto. Subversivosy malditos en la Universidad de Sevilla (1965-1977). Sevilla: Fundación Centro de Estudios Andaluces, 2008.

CARRILlo-LinARES, AlBERTo. "Sin corbata y con melena: imágenes y representaciones de los estudiantes sesentayochistas". En Globalizing the student rebellion in the long' 68, editado por Andrés Payá Rico y otros. Salamanca: FarenHouse, 2018.

Carrillo-Linares, Alberto y Sergio Rodríguez Tejada, "1968 y los estudiantes españoles: del antifranquismo a la revolución”. En Las convulsiones del 68. España y el sur de Europa, coordinado por Abdón Mateos López y Emanuele Treglia. Madrid: UNED, 2019.

Clifford, Rebecca; Robert Gildea y Anette Warring. "Gender and sexuality”. En Europe's 1968. Voices of Revolt, editado por Robert Gildea, James Mark y Anette Warring. Oxford: Oxford University Press, 2013.

Colomer, Josep María. “¿Dónde están los estudiantes radicales del 68?”. Triunfo, 17 de junio de 1978.

Contreras-Becerra, JAvier. "Margarita María Birriel Salcedo. Activismo ciudadano". Andalucía en la Historia, 57 (2017): 35-37.

Cucó I Giner, JosePA. De la utopia revolucionària a l'activisme social. El Moviment Comunista, Revolta i Cristina Piris, Valencia: PUV, 2016.

De Miguel, Amando. Carta abierta a una universitaria. Madrid: Ediciones 99, 1973.

Díaz, Irene; José G. Alén y Rubén VegA, Cristina, Manuela y Paca. Tres vidas cruzadas, entre la justicia y el compromiso. Barcelona: Península, 2017.

Evans, SARA M. "Sons, Daughters and Patriarchy. Gender and the 1968 Generation". American Historical Review, 114 (2009): 331-347.

Frazier, Lessie Jo y Deborah Cohen, eds., Gender and Sexuality in 1968. Transformative Politics in the Cultural Imagination. Nueva York: Palgrave MacMillan, 2009. 
García de León, María Antonia. Rebeldes ilustradas (la otra Transición). Barcelona: Anthropos, 2008.

Giallongo, AngEla. "Alcune riflessioni sulle emozioni del Movimento Studentesco: Italia 1968". En Globalizing the student rebellion in the long' 68, editado por Andrés Payá Rico y otros. Salamanca: FarenHouse, 2018.

González CAlleja, EduARdo. "Rebelión en las aulas: un siglo de movilizaciones estudiantiles en España (1865-1968)". Ayer, 59 (2005): 21-49.

Hernández Sandoica, Elena; Miguel Ángel Ruiz Carnicer y Marc Balcó LACOMBA, Estudiantes contra Franco (1939-1975). Oposición política y movilización juvenil. Madrid: La Esfera de los Libros, 2007.

IgLESIAS, MAGis. Fuimos nosotras. Las primeras parlamentarias de la democracia. Madrid: Debate, 2019.

Kornetis, Kostis. Children of the dictatorship. Student Resistance, Cultural Politics and the 'Long 1960s' in Greece. New York-Oxford: Berhahn Books, 2013.

KoRNETIS, Kostis. "Let's get laid because it's the end of the world': sexuality, gender and the Spanish Left in late Fracoism and the Transición". European Review of History, 22, no.1 (2015): 176-198.

LABRADOR MÉNDEZ, GERMÁN. Culpables por la literatura. Imaginación política y contracultura en la transición española (1968-1986). Madrid: Akal, 2017.

MaIllaRd, Ma ${ }^{a}$ LuISA. Asociación Española de Mujeres Universitarias (19201990). Madrid: Instituto de la Mujer, 1990.

Maravall, José María. Dictadura y disentimiento político. Obreros y estudiantes bajo el franquismo. Madrid: Alfaguara, 1978.

Moreno Seco, Mónica y Bárbara Ortuño Martínez, "Presentación" al dosier "Género, juventud y compromiso". Ayer, 100 (2015): 13-20.

Moreno SECo, MóniCA. "Sexo, Marx y nova cançó. Género, política y vida privada en la juventud comunista de los años setenta". Historia Contemporánea, 54 (2017): 47-84.

Moreno Seco, MónicA. "Entre la disciplina y la transgresión. Pilar Brabo, dirigente y diputada comunista en la Transición“. Spagna Contemporanea, 55 (2019): 83-102.

Moreno SECo, MónICA. “Género, transgresión y militancia en la izquierda radical de los años setenta". En Mujeres, dones, mulleres, emakumeak. Estudios sobre la historia de las mujeres y del género, editado por Teresa María Ortega López, Ana Aguado Higón y Elena Hernández Sandoica. Madrid: Cátedra, 2019.

NASH, MARY. Dones en transició. Barcelona: Ajuntament de Barcelona, 2007. 
PADILla, JAVIER. A finales de enero. La historia de amor más trágica de la Transición. Barcelona: Tusquets, 2019.

PALA, GIAIME. "Entre paternalismo e igualitarismo. El PSUC y la cuestión de la mujer en los años del tardofranquismo". Mientras Tanto, 97 (2005): 133-148.

PaPAdogiannis, Nikolaos. “Confronting 'Imperialism' and 'loneliness': Sexual and gender relations among young Communists in Greece, 19741981". Journal of Modern Greek Studies, 29, no. 2 (2011): 219-250.

Revilla Castro, Juan CaRlos. "La construcción discursiva de la juventud: lo general y lo particular”. Papers, 63/64 (2001): 103-122.

Rodríguez TejadA, SERgio. "Compañeras: la militancia de las mujeres en el movimiento estudiantil antifranquista en Valencia". Historia del Presente, 4 (2004): 123-146.

RodríGuez TEJADA, SERGIO. Zonas de libertad. II-Dictadura franquista y movimiento estudiantil en la Universidad de Valencia (1965-1975). Valencia: PUV, 2009.

Rodríguez TejadA, Sergio. "Partido comunista y movimiento estudiantil durante el franquismo". En Nosotros los comunistas: memoria, identidad e historia social, editado por Manuel Bueno Lluch y Sergio Gálvez Biesca. Sevilla: FIM-Atrapasueños, 2009.

SANZ Díaz, Benito. L'oposició universitària al franquisme. València, 19391975. Valencia: Universitat de Valencia, 2013.

SESEÑA, NATACHA. "AEMU (1920-1990). Setenta años de labor seria y libre a favor de la mujer". En El movimiento feminista en España en los años 70, editado por Carmen Martínez Ten, Purificación Gutiérrez López y Pilar González Ruiz. Madrid: Cátedra, 2009.

Varela Fernández, Julia; Pilar Parra Contreras y Alejandra Val CubeRo, Memorias para hacer camino: relatos de vida de once mujeres españolas de la generación del 68. Madrid: Morata, 2016.

VARo Moral, NADIA. "Mujeres y hombres: la 'represión sexuada' de la militancia política". En Resistencia ordinaria. La militancia y el antifranquismo catalán ante el Tribunal de Orden Público (1963-1977), editado por Javier Tébar Hurtado. Valencia: PUV, 2012.

Verdugo, Vicenta. "Mujeres jóvenes en la Transición Democrática: la Coordinadora y la Asamblea de Mujeres de Valencia". Historia Contemporánea, 54 (2017): 85-113.

ZANCARINI-FouRnel, Michelle. “Genre et politique: Les années 68”. Vingtième Siècle. Revue d'histoire, 75 (2002): 133-143. 